\title{
Rainfall erosivity estimation based on rainfall data collected over a range of temporal resolutions
}

\author{
S. Yin ${ }^{1,2}$, Y. Xie ${ }^{1,2}$, B. Liu ${ }^{1,2}$, and M. A. Nearing ${ }^{3}$ \\ ${ }^{1}$ State Key Laboratory of Earth Surface Processes and Resource Ecology, Beijing Normal University, Beijing 100875, China \\ ${ }^{2}$ School of Geography, Beijing Normal University, Beijing 100875, China \\ ${ }^{3}$ USDA-ARS Southwest Watershed Research Center, Tucson, AZ 85719, USA
}

Correspondence to: S. Yin (yinshuiqing@bnu.edu.cn)

Received: 22 April 2015 - Published in Hydrol. Earth Syst. Sci. Discuss.: 20 May 2015

Revised: 11 September 2015 - Accepted: 27 September 2015 - Published: 9 October 2015

\begin{abstract}
Rainfall erosivity is the power of rainfall to cause soil erosion by water. The rainfall erosivity index for a rainfall event (energy-intensity values $-E I_{30}$ ) is calculated from the total kinetic energy and maximum 30 min intensity of individual events. However, these data are often unavailable in many areas of the world. The purpose of this study was to develop models based on commonly available rainfall data resolutions, such as daily or monthly totals, to calculate rainfall erosivity. Eleven stations with 1 min temporal resolution rainfall data collected from 1961 through 2000 in the eastern half of China were used to develop and calibrate 21 models. Seven independent stations, also with $1 \mathrm{~min}$ data, were utilized to validate those models, together with 20 previously published equations. The models in this study performed better or similar to models from previous research to estimate rainfall erosivity for these data. Using symmetric mean absolute percentage errors and Nash-Sutcliffe model efficiency coefficients, we can recommend 17 of the new models that had model efficiencies $\geq 0.59$. The best prediction capabilities resulted from using the finest resolution rainfall data as inputs at a given erosivity timescale and by summing results from equations for finer erosivity timescales where possible. Results from this study provide a number of options for developing erosivity maps using coarse resolution rainfall data.
\end{abstract}

\section{Introduction}

Soil erosion prediction models are effective tools for helping to guide and inform soil conservation planning and practice. The most widely used soil erosion models used for conserva- tion planning are derived from the Universal Soil Loss Equation (USLE) (Wischmeier and Smith, 1965, 1978). These models include the USLE, the Revised USLE (RUSLE) (Renard et al., 1997), and RUSLE2 (Foster, 2004). Adaptations of the USLE have also been developed for use in other parts of the world, including, for example, Germany (Schwertmann et al., 1990), Russia (Larionov, 1993), and China (Liu et al., 2002). For example, the Chinese Soil Loss Equation (CSLE) was used in the first national water erosion sample survey in China (Liu et al., 2013).

These models have in common a rainfall erosivity factor $(R)$, which reflects the potential capability of rainfall to cause soil loss from hillslopes, and which is one of the most important basic factors for estimating soil erosion. In its simplest form, the $R$ factor is an average annual value, calculated as a summation of event-based energy-intensity values $\left(E I_{30}\right)$ for a location divided by the number of years over which the data were collected. $E I_{30}$ is defined as the product of kinetic energy of rainfall and the maximum contiguous 30 min rainfall intensity during the rainfall event. It is the basic rainfall erosivity index that was developed by Wischmeier (1958) originally for the USLE, and is still widely used in other erosion prediction models (e.g., RUSLE, RUSLE2), with some modifications and improvements. Wischmeier (1976) suggested that more than 20 years' rainfall data are needed to calculate average annual erosivity to include relatively dry and wet periods.

Determination of the maximum contiguous 30 min rainfall intensity during the rainfall event is a relatively straightforward process, although it requires a temporally detailed 
rainfall record (e.g., $5 \mathrm{~min}$ ) for a storm. Determination of the kinetic energy of a storm is more complex.

Kinetic energy (KE) is generally suggested to indicate the ability of a raindrop to detach soil particles from a soil mass (e.g., Nearing and Bradford, 1985). Since the direct measurement of KE requires sophisticated and costly instruments, several different estimating methods have been developed that estimate KE based on rainfall intensity $(I)$ using logarithmic, exponential, or power functions. The original 1978 release of the USLE utilized a logarithmic function (Wischmeier and Smith, 1978) that was based on rainfall energy data published by Laws and Parsons (1943). Brown and Foster (1987) re-evaluated this relationship and recommended the use of an exponential relationship, which was subsequently used in RUSLE (Renard et al., 1997). For RUSLE2 Foster (2004) used the exponent value of -0.082 , rather than the -0.05 value used in RUSLE, as follows:

$e_{r}=0.29\left[1-0.72 \exp \left(-0.082 i_{r}\right)\right]$,

where $e_{r}$ is the estimated unit rainfall kinetic energy $\left(\mathrm{MJ} \mathrm{ha}^{-1} \mathrm{~mm}^{-1}\right)$ and $i_{r}$ is the rainfall intensity $\left(\mathrm{mm} \mathrm{h}^{-1}\right)$ at any given time within a rainfall event (usually taken as $1 \mathrm{~min}$ for computational purposes, with average-intensity representative of the time increment). This was based largely on work of McGregor and Mutchler (1976) and McGregor et al. (1995), who found that the RUSLE equation gave values that were too low. The energy term used in RUSLE2 gives results on the order of those from the original USLE method.

The temporal resolution of rainfall data available across the world does not always allow for a direct computation of rainfall kinetic energy (Sadeghi et al., 2011; Sadeghi and Tavangar, 2015; Oliveira et al., 2012; Panagos et al., 2015; Zhang and Fu, 2003), even within countries with extensive rainfall monitoring programs. In the United States, for example, intra-storm, temporally detailed data (historically taken on pen recording charts, now taken as 1 min digital data) are only available at limited stations, whereas daily data are common (Nicks and Lane, 1995; Flanagan et al., 2001). Yet there is a need for developing models for application in all areas of the world in order to produce erosivity maps that can be used for evaluating soil erosion rates (e.g., Sadeghi et al., 2011, Sadeghi and Tavangar, 2015; Oliveira et al., 2012; Panagos et al., 2015; Zhang and Fu, 2003). For that reason many efforts have been undertaken to estimate rainfall erosivity by using daily (Richardson et al., 1983; Yu, 1998; Capolongo et al., 2008; Yin et al., 2007; Zhang et al., 2002a, b; Xie et al., 2001, 2015), monthly (Arnoldus, 1977; Renard and Freimund, 1994; Yu and Rosewell, 1996; Ferro et al., 1999; Wu, 1994; Zhou et al., 1995), or annual rainfall data (Lo et al., 1985; Renard and Freimund, 1994; Yu and Rosewell, 1996; Bonilla and Vidal, 2011; Zhang and Fu, 2003; Wang, 1987; Sun, 1990). Generally the technique has been to develop a simple empirical relationship between erosivity and coarse resolution rainfall based on limited finer resolution data and then to extend the analyses to wider areas and longer periods with coarser temporal resolution rainfall data (Angulo-Martinez and Begueria, 2012; Ma et al., 2014; Ramos and Duran, 2014; Sanchez-Moreno et al., 2014).

Several studies evaluated different timescales of erosivity using different temporal resolutions of rainfall data. In Europe, Panagos et al. (2015) undertook the task to develop an erosivity map for Europe based on data from 1541 precipitation stations with temporal resolutions of 5 to $60 \mathrm{~min}$. To use data that had been reported at the different time resolutions they had to apply adjustment factors to the data, which they reported to have introduced some uncertainty into the estimations. Sadeghi and Tavangar (2015) evaluated various erosivity estimation indices, including Fournier (Fournier, 1960), modified Fournier (Arnoldus, 1977), Roose (1977) and Lo et al. (1985), using data from 14 stations in Iran. They evaluated annual, seasonal, and monthly information. Similarly, the work in Brazil summarized by Oliveira et al. (2012) highlighted several studies that used various estimations of erosivity based on various types of data and interpolations. Other innovative ways have been advanced to produce better mappings of erosivity, including the use of daily (Fan et al., 2013) or $3 \mathrm{~h}$ (Vrieling et al., 2010, 2014) data from the Tropical Rainfall Measuring Mission (TRMM) Multi-satellite Precipitation Analysis (TMPA) precipitation data.

In China the specifications for surface meteorological observations by the China Meteorological Administration (China Meteorological Administration, 2003) have required since the 1950s that the maximum 60 and $10 \mathrm{~min}$ rainfall amounts, $\left(P_{60}\right)_{\text {day }}$ and $\left(P_{10}\right)_{\text {day }}$, be compiled; hence, these data are readily available in China. The measurements were made using siphon-method, self-recording rain gauges. Because of this, there is an interest in China to utilize the maximum daily 10 and $60 \mathrm{~min}$ rainfall intensities, $\left(I_{10}\right)_{\text {day }}$ and $\left(I_{60}\right)_{\text {day }}$, to calculate erosivity.

The objectives of this study were threefold: (1) calibrate methods of estimating erosivity for timescales ranging from daily to average annual based on different temporal resolutions of rainfall data from 11 calibration stations with $1 \mathrm{~min}$ resolution data; (2) compare models in this study with those published in previous research, based on seven independent validation stations using the same data types; and (3) determine the most accurate methods, based on these data, for calculating different timescales of erosivity when different temporal resolutions of rainfall data are available. Note that, in this paper, we use the term timescales when discussing the erosivity values (equation outputs) and resolution (equation inputs) when referring to the rainfall input data, for clarity. Although several studies have been conducted on this topic in the past, no study used as comprehensive a data set collected over this wide geographic area of China to evaluate the wide range of erosivity timescales needed for erosion work, and utilizing such a wide range of temporal resolution rainfall data as the independent variable. 


\section{Data and methods}

\subsection{Data}

Data collected at 18 stations by the Meteorological $\mathrm{Bu}$ reaus of Heilongjiang, Shanxi, Shaanxi, Sichuan, Hubei, Fujian, and Yunnan provinces and the municipality of Beijing were used (Fig. 1, Table 1). These stations were distributed over the eastern half of China; $1 \mathrm{~min}$ resolution rainfall data (Data M) were obtained by using a siphon, self-recording rain gauge. The data collection period began in 1971 for Wuzhai (53663) and Yangcheng (53975) in Shanxi Province and from 1961 for the remaining 16 stations; the data records ended in 2000 for all stations. Quality control of Data M was done to select the best observation years using the more complete data sets of daily rainfall totals, Data D, which were observed by simple rain gauges at the same stations. Data M was compared with Data D on a day-by-day basis, and those days with deviation exceeding a certain criterion were marked as questionable and were not used in this analysis (Wang et al., 2004). The criterion used was that the data were considered good when the absolute deviation between Data $\mathrm{M}$ and Data $\mathrm{D}$ was less than $0.5 \mathrm{~mm}$ when the daily rainfall amount was less than $5 \mathrm{~mm}$ and no more than $10 \%$ when the daily rainfall amount was greater than or equal to $5 \mathrm{~mm}$. Data $\mathrm{M}$ in the earlier years of record tended to have more days with missing or suspicious observations. These totals of Data $\mathrm{M}$ and Data D were compared year-by-year to determine which years could be designated as common years for use in this study, with an effective year having a relative deviation for yearly rainfall amount of no more than $15 \%$. There were at least 29 common years for all 18 stations, and seven stations had common years of at least 38 years (Table 1). Note that though there were missing data in the information used, Data D was only used for quality control purposes and the data used in the analysis, Data M, were internally consistent in that only the data from common years were used in all comparisons and evaluations reported.

Data $\mathrm{M}$ was used to calculate the event-based $E I_{30}$ values as a function of the calculated kinetic energy and maximum 30 min rainfall intensity (Foster, 2004). These were treated as observed values and summed to obtain the erosivity factors, $R$, for daily, month (individual month totals), year (individual year totals), average monthly (one value for each month at each station), and average annual (one value for each station) timescales. Total rainfall event depth values were also compiled into the other temporal resolutions of rainfall data, including correspondent daily, month, year, average monthly, and average annual resolutions. For the eight stations in the northern part of China (including stations in Heilongjiang, Shanxi, Shaanxi provinces and Beijing municipality), only the periods from May through September were used because the siphon, self-recording rain gauges were not utilized in the winter to avoid freeze damage. Percentages of precipitation during May through September to total annual precipitation varied from 75.6 to $89.2 \%$ for these eight northern stations. Data $\mathrm{M}$ for the full 12 month year was used from the remaining 10 stations located in the southern parts of China.

Eleven stations, including Nenjiang, Wuzhai, Suide, Yan'an, Guangxiangtai, Chengdu, Suining, Neijiang, Fangxian, Kunming, and Fuzhou, marked with dots in Fig. 1, were used to calibrate the models (Table 1). The other seven stations, including Tonghe, Yangcheng, Miyun, Xichang, Huangshi, Tengchong, and Changting, marked with triangles in Fig. 1, were used to validate the models.

\subsection{Calculation of the $\boldsymbol{R}$ factor at different timescales}

Different timescales for RUSLE2 erosivity, $R$, including event, daily, month, year, average monthly, and average annual, were calculated based on the 1 min resolution data (Data M). Recall that month and year refer to individual months and years, and not averages. $E I_{30}\left(\mathrm{MJ} \mathrm{mm} \mathrm{ha}^{-1} \mathrm{~h}^{-1}\right)$ is the rainfall erosivity index for a rainfall event, where $E$ is the total rainfall kinetic energy during an event and $I_{30}$ is the maximum contiguous 30 min intensity during an event (Wischmeier and Smith, 1978). An individual rainfall event was defined as a period of rainfall with at least six preceding and six succeeding non-precipitation hours (Wischmeier and Smith, 1978). An erosive rainfall event was defined as one with rainfall amounts greater than or equal to $12 \mathrm{~mm}$, following Xie et al. (2002). We used the equation recommended by Foster 2004) for RUSLE2 to calculate the kinetic energy of the storms, which used Eq. (1) combined with

$E=\sum_{r=1}^{n}\left(e_{\mathrm{r}} \cdot \mathrm{P}_{r}\right)$,

where $e_{r}$ is the estimated unit rainfall kinetic energy (from Eq. 1) for the $r$ th minute (MJ ha ${ }^{-1} \mathrm{~mm}^{-1}$ ); $P_{r}$ is the $1 \mathrm{~min}$ rainfall amount for the $r$ th minute $(\mathrm{mm}) ; r=1,2, \ldots, n$ represents each $1 \mathrm{~min}$ interval in the storm; and $i_{r}$ is the rainfall intensity for the $r$ th minute $\left(\mathrm{mm} \mathrm{h}^{-1}\right)$. The Foster (2004) equations were chosen because they are currently used for erosion assessment for RUSLE2 in the United States and for the CSLE in China, and it appears to give results similar to the original USLE, as was discussed in the Introduction.

Our evaluation included four models for events and one for daily erosivities. Event models were simply models to predict individual event erosivities, regardless of whether they occurred in 1 or more days, and regardless of whether more than one event occurred in a day. For the daily model, rainfall erosivity for each day, $R_{\mathrm{day}}$, was calculated following the method by Xie et al. (2015). When a day had only one erosive event and this event began and finished during the same day, then

$R_{\text {day }}=E I_{30}$. 


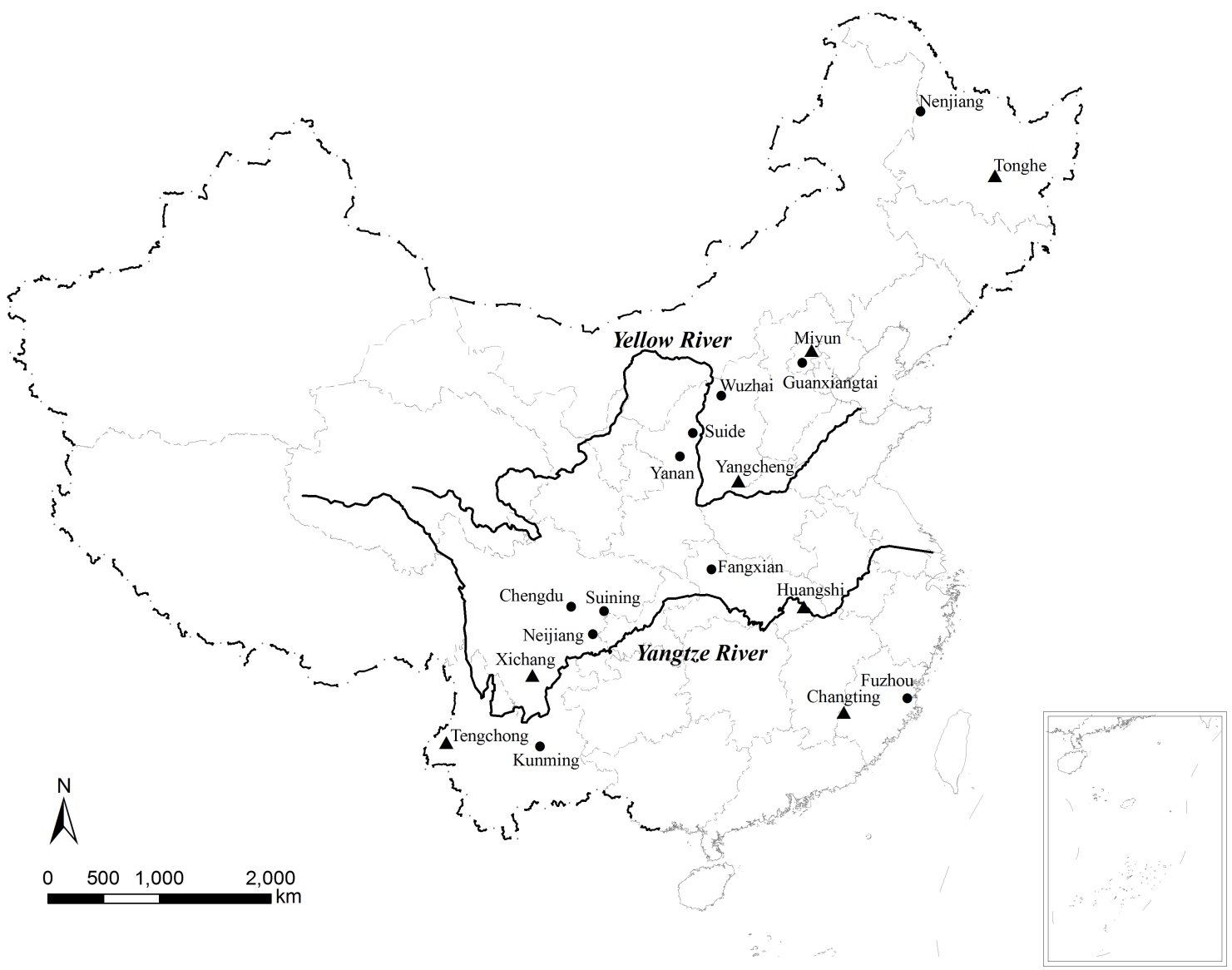

Figure 1. Locations of the 18 stations with 1 min resolution rainfall data. Eleven stations marked with dots were used to calibrate 21 models. The other seven stations marked with triangles were used to validate models and conduct comparisons with previous research.

When more than one full rainfall event happened during 1 day, then

$R_{\text {day }}=\sum_{\mathrm{i}=1}^{\mathrm{n}} E_{\text {event } \_i} \cdot\left(I_{30}\right)_{\text {event } \_i}$,

where $n$ is the number of rainfall events during the day, and $E_{\text {event } \_i}$ and $\left(I_{30}\right)_{\text {event } \_i}$ are the total rainfall energy and the maximum contiguous $30 \mathrm{~min}$ intensity, respectively, for the $i$ th event. When only one part of a rainfall event occurred during 1 day, then

$R_{\text {day }}=E_{\text {day } \_d} \cdot\left(I_{30},\right)_{\text {event }}$,

where $E_{\text {day } \_d} d$ is the rainfall energy generated by the part of rainfall occurred during the $d$ th day and $\left(I_{30}\right)_{\text {event }}$ is the maximum contiguous $30 \mathrm{~min}$ intensity for the entire event. The remaining situations were calculated by combining Eqs. (4) and (5).

Month, year, average monthly, and average annual $R$ values were summed from the event $E I_{30}$ index by erosive storms that occurred during the corresponding period. They were calculated by using Eqs. (6)-(9).

$$
\begin{aligned}
& R_{\text {month, } y, m}=\sum_{j=0}^{J}\left(E I_{30}\right)_{y, m, j}, \\
& R_{\text {ave_month, } m}=\frac{1}{Y} \sum_{y=1}^{Y} R_{\text {month, } y, m}, \\
& R_{\text {year }, y}=\sum_{m=1}^{12} R_{\text {month, } y, m}, \\
& R_{\text {ave_annual }}=\sum_{y=1}^{Y} R_{\text {year }, y},
\end{aligned}
$$

where $y$ is the number of years of record; $\left(E I_{30}\right)_{y, m, j}$ is the $E I_{30}$ value for the $j$ th event in the $m$ th month of the $y$ th year; $R_{\text {month, } y, m}$ is the $R$ value for the $m$ th month of the $y$ th year; $R_{\text {ave_month, } \mathrm{m}}$ is the average $R$ value for the $m$ th month over the years of record; $R_{\text {year, } y}$ is $R$ value in the $y$ th year; and $R_{\text {ave_annual }}$ represents average annual erosivity, correspondent to the annual average $R$ factor in USLE-type models (MJ mm ha ${ }^{-1} \mathrm{~h}^{-1} \mathrm{a}^{-1}$ ). 
Table 1. Information for the 18 rainfall stations.

\begin{tabular}{|c|c|c|c|c|c|c|c|c|}
\hline Province & $\begin{array}{l}\text { Station } \\
\text { name }\end{array}$ & $\begin{array}{l}\text { Lat. } \\
\left({ }^{\circ} \mathrm{N}\right)\end{array}$ & $\begin{array}{l}\text { Long. } \\
\left({ }^{\circ} \mathrm{E}\right)\end{array}$ & $\begin{array}{l}\text { Elevation } \\
\text { (m) }\end{array}$ & $\begin{array}{l}\text { Effective } \\
\text { years }\end{array}$ & $\begin{array}{l}\text { No. of } \\
\text { erosive } \\
\text { events }\end{array}$ & $\begin{array}{l}\text { Annual } \\
\text { rainfall }^{3} \\
(\mathrm{~mm})\end{array}$ & $\begin{array}{l}R^{4} \\
\left(\mathrm{MJ} \mathrm{mm} \mathrm{ha}^{-1}\right. \\
\left.\mathrm{h}^{-1} \mathrm{a}^{-1}\right)\end{array}$ \\
\hline \multirow[t]{2}{*}{ Heilongjiang ${ }^{1}$} & Nenjiang & 49.17 & 125.23 & 243.0 & 30 & 343 & 485.8 & 1368.7 \\
\hline & Tonghe $^{2}$ & 45.97 & 128.73 & 110.0 & 38 & 471 & 596.2 & 1632.5 \\
\hline \multirow[t]{2}{*}{ Shanxi ${ }^{1}$} & Wuzhai & 38.92 & 111.82 & 1402.0 & 30 & 289 & 464.0 & 781.9 \\
\hline & Yangcheng $^{2}$ & 35.48 & 112.4 & 658.8 & 30 & 340 & 605.9 & 1503.3 \\
\hline \multirow[t]{2}{*}{ Shaanxi ${ }^{1}$} & Suide & 37.5 & 110.22 & 928.5 & 29 & 256 & 449.7 & 992.8 \\
\hline & Yan'an & 36.6 & 109.5 & 958.8 & 39 & 411 & 534.6 & 1233.7 \\
\hline \multirow[t]{2}{*}{ Beijing $^{1}$} & Guanxiangtai & 39.93 & 116.28 & 54.7 & 40 & 434 & 575.0 & 3188.1 \\
\hline & Miyun $^{2}$ & 40.38 & 116.87 & 73.1 & 37 & 476 & 648.1 & 3575.0 \\
\hline \multirow[t]{4}{*}{ Sichuan } & Chengdu & 30.67 & 104.02 & 506.1 & 39 & 717 & 891.8 & 3977.0 \\
\hline & Xichang $^{2}$ & 27.9 & 102.27 & 1590.9 & 40 & 998 & 1007.5 & 3021.0 \\
\hline & Suining & 30.5 & 105.58 & 279.5 & 33 & 654 & 932.7 & 4091.3 \\
\hline & Neijiang & 29.58 & 105.05 & 352.4 & 39 & 826 & 1034.1 & 5097.9 \\
\hline \multirow[t]{2}{*}{ Hubei } & Fangxian & 32.03 & 110.77 & 427.1 & 31 & 563 & 829.5 & 2298.4 \\
\hline & Huangshi $^{2}$ & 30.25 & 115.05 & 20.6 & 32 & 898 & 1438.5 & 6049.4 \\
\hline \multirow[t]{2}{*}{ Yunnan } & Tengchong ${ }^{2}$ & 25.02 & 98.5 & 1648.7 & 36 & 1205 & 1495.7 & 3648.9 \\
\hline & Kunming & 25.02 & 102.68 & 1896.8 & 33 & 747 & 1018.8 & 3479.0 \\
\hline \multirow[t]{2}{*}{ Fujian } & Fuzhou & 26.08 & 119.28 & 84.0 & 39 & 1136 & 1365.4 & 5871.1 \\
\hline & Changting $^{2}$ & 25.85 & 116.37 & 311.2 & 31 & 1037 & 1728.1 & 8258.5 \\
\hline
\end{tabular}

\footnotetext{
1 The eight stations in these provinces are located in the northern part of China and had 1 min resolution data collected from May through September. The remaining ten stations were based on data collected during the entire year. ${ }^{2}$ Seven validation stations (the other 11 stations were calibration stations.) ${ }^{3}$ Based on daily rainfall data sets collected during $1961-2000 .{ }^{4} R$ in this case is the average annual erosivity.
}

\subsection{Model calibration using different resolutions of rainfall data}

A total of 21 models were calibrated for different timescales of $R$, based on varying resolutions of rainfall data (Table 2). Event amount $P_{\text {event }}$ and peak-intensity indices were derived based on the $1 \mathrm{~min}$ resolution data, including $I_{10}, I_{30}$, and $I_{60}$, which were the maximum contiguous 10,30 , and $60 \mathrm{~min}$ intensities, respectively, within an event. $I_{10}$ and $I_{60}$ were used because of their close correlation with the daily $\left(I_{10}\right)_{\text {day }}$ and $\left(I_{60}\right)_{\text {day }}$ values commonly reported by the Chinese Meteorological Administration (2003). Four event-based models were developed relating measured $E I_{30}$ to estimated $E I_{30}$ (Table 2). Similar models for the other timescales were also calibrated (Table 2). Data were organized in various ways. $P_{\text {day }}, P_{\text {month }}, P_{\text {year }}, P_{\text {ave_month }}$, and $P_{\text {annual }}$ were the daily, (individual) month, (individual) year, average monthly, and average annual rainfall amounts, respectively, for a given station. $\left(P_{60}\right)_{\text {month }}$ and $\left(P_{60}\right)_{\text {year }}$ represented maximum contiguous $60 \mathrm{~min}$ rainfall amount observed within a specific month or year, respectively. $\left(P_{60}\right)_{\text {month_max }}$ represented the maximum of $\left(P_{60}\right)_{\text {month }}$ values for each month of the year over the entire period of record. The average of $\left(P_{60}\right)_{\text {month }}$ values was $\overline{\left(P_{60}\right)_{\text {month }}}$. Each station had 12 values of $\left(P_{60}\right)_{\text {month_max }}$ and $\overline{\left(P_{60}\right)_{\text {month }}}$, one for each month of the year. $\left(P_{60}\right)_{\text {year_max }}$ was the maximum value of $\left(P_{60}\right)_{\text {year }}$ and $\overline{\left(P_{60}\right)_{\text {annual }}}$ was the average of $\left(P_{60}\right)_{\text {year }}$ values. Each station had only one value for these two parameters. $P_{1440}$ was daily rainfall amount and its related index, including $\left(P_{1440}\right)_{\text {month }}$, $\left(P_{1440}\right)_{\text {year }},\left(P_{1440}\right)_{\text {month_max }}, \overline{\left(P_{1440}\right)_{\text {month }}},\left(P_{1440}\right)_{\text {year_max }}$, and $\overline{\left(P_{1440}\right)_{\text {annual }}}$, which were defined in an analogous way as were correspondent values for $P_{60}$.

The parameters were obtained station-by-station for calibration stations first and parameters for linear relationships were compared to determine if data from all stations could be pooled together to conduct the regressions (Snedecor and Cochran, 1989). Parameters for power-law models, including Month I, Year I, Average Monthly I, and Annual I (Table 2), were obtained by using the Levenberg-Marquardt algorithm (Seber and Wild, 2003). Note that models coded as Annual refer to annual averages.

\subsection{Models published in previous research for comparison}

In addition to the 21 new models presented here, 20 representative models developed using data from China in previous research were also compared (Table 3). For these models other variables were needed. $P_{d 12}$ was average daily erosive rainfall total and $P_{y 12}$ was average annual erosive rainfall total. $P_{5-10}$ represented the rainy season rainfall amount from May through October for a specific year. $P_{\geq 10 \text { year was the }}$ summation of daily rainfall no less than $10 \mathrm{~mm}$ in a year and

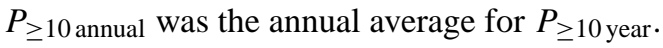


Table 2. Models calibrated.

\begin{tabular}{llll}
\hline Model codes & Models & Model codes & Models \\
\hline Event I & $E I_{30}=\lambda_{1} P_{\text {event }} I_{10}$ & Average Monthly I & $R_{\text {ave_month }}=\alpha_{3} P_{\text {ave_month }}^{\beta_{3}}$ \\
Event II & $E I_{30}=\lambda_{2} P_{\text {event }} I_{30}$ & Average Monthly II & $R_{\text {ave_month }}=\lambda_{11} P_{\text {ave_month }}\left(P_{60}\right)_{\text {month_max }}$ \\
Event III & $E I_{30}=\lambda_{3} P_{\text {event }} I_{60}$ & Average Monthly III & $R_{\text {ave_month }}=\lambda_{12} P_{\text {ave_month }}\left(P_{1440}\right)_{\text {month_max }}$ \\
Event IV & $E I_{30}=\lambda_{4} P_{\text {event }} I_{30} \quad I_{30}<15 \mathrm{mmh}^{-1}$ & Average Monthly IV & $R_{\text {ave_month }}=\lambda_{13} P_{\text {ave_month }} \overline{\left(P_{60}\right)_{\text {month }}}$ \\
& $E I_{30}=\lambda_{5} P_{\text {event }} I_{30} \quad I_{30} \geq 15 \mathrm{mmh}^{-1}$ & & \\
Daily I & $R_{\text {day }}=\lambda_{6} P_{\text {day }}\left(I_{10}\right)_{\text {day }}$ & Average Monthly V V & $R_{\text {ave_month }}=\lambda_{14} P_{\text {ave_month }} \overline{\left(P_{1440}\right)_{\text {month }}}$ \\
Monthly I & $R_{\text {month }}=\alpha_{1} P_{\text {month }}^{\beta 1}$ & Annual I* & $R_{\text {annual }}=\alpha_{4} P_{\text {annual }} \beta_{4}$ \\
Monthly II & $R_{\text {month }}=\lambda_{7} P_{\text {month }}\left(P_{60}\right)_{\text {month }}$ & Annual II & $R_{\text {annual }}=\lambda_{15} P_{\text {annual }}\left(P_{60}\right)_{\text {year_max }}$ \\
Monthly III & $R_{\text {month }}=\lambda_{8} P_{\text {month }}\left(P_{1440}\right)_{\text {month }}$ & Annual III & $R_{\text {annual }}=\lambda_{16} P_{\text {annual }}\left(P_{1440}\right)_{\text {year_max }}$ \\
Yearly I & $R_{\text {year }}=\alpha_{2} P_{\text {year }}^{\beta_{2}}$ & $R_{\text {annual }}=\lambda_{17} P_{\text {annual }} \overline{\left(P_{60}\right)_{\text {annual }}}$ \\
Yearly II & $R_{\text {year }}=\lambda_{9} P_{\text {year }}\left(P_{60}\right)_{\text {year }}$ & Annual IV & $R_{\text {annual }}=\lambda_{18} P_{\text {annual }} \overline{\left(P_{1440}\right)_{\text {annual }}}$ \\
Yearly III & $R_{\text {year }}=\lambda_{10} P_{\text {year }}\left(P_{1440}\right)_{\text {year }}$ & Annual V & \\
\hline
\end{tabular}

* Annual refers to Average Annual values of erosivity.

Table 3. Models published in previous research and their prediction capabilities determined using the validation stations - the symmetric

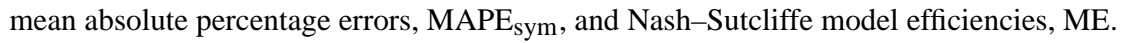

\begin{tabular}{|c|c|c|c|c|}
\hline $\begin{array}{l}\text { Erosivity time } \\
\text { scales }\end{array}$ & Models & Sources & $\begin{array}{r}\text { MAPE }_{\text {sym }} \\
(\%)^{1}\end{array}$ & $\mathrm{ME}^{2}$ \\
\hline \multirow[t]{5}{*}{ Event } & $R_{\text {event }}=9.8 \cdot\left(0.0247 P_{\text {event }} I_{30}-0.17\right)$ & Wang (1987) & 27.8 & 0.98 \\
\hline & $R_{\text {event }}=9.8 \cdot\left(0.025 P_{\text {event }} I_{30}-0.32\right)$ & Wang (1987) & 26.1 & 0.98 \\
\hline & $R_{\text {event }}=9.8 \cdot\left(1.70 \frac{P_{\text {event }} I_{30}}{100}-0.136\right) \quad I_{30}<10 m h^{-1}$ & Wano et al (1995) & 138 & 098 \\
\hline & $R_{\text {event }}=9.8 \cdot\left(2.35 \frac{P_{\mathrm{event}} I_{30}}{100}-0.523\right) \quad I_{30} \geq 10 m m^{-1}$ & Wang et al. (1995) & 13.8 & 0.98 \\
\hline & $R_{\text {event }}=0.1773 P_{\text {event }} I_{10}$ & Zhang et al. (2002a) & 44.7 & 0.89 \\
\hline \multirow[t]{5}{*}{ Daily } & $R_{\text {day }}=0.184 P_{\text {day }}\left(I_{10}\right)_{\text {day }}$ & Xie et al. (2001) & 44.9 & 0.91 \\
\hline & $R_{\text {day }}=\alpha P_{\text {day }}^{\beta}$ & Zhang et al. (2002b) & 74.6 & 0.69 \\
\hline & $\beta=0.8363+\frac{18.144}{P_{d 12}}+\frac{24.455}{P_{y 12}}, \alpha=21.586 \beta^{-7.1891}$ & & & \\
\hline & $R_{\text {day }}=0.2686\left[1+0.5412 \cos \left(\frac{\pi}{6} j-\frac{7 \pi}{6}\right)\right] P_{\text {day }}^{1.7265}$ & Xie et al. (2015) & 63.7 & 0.71 \\
\hline & $R_{\text {day }}=0.3522 P_{\text {day }}\left(P_{60}\right)_{\text {day }}$ & Xie et al. (2015) & 38.2 & 0.95 \\
\hline \multirow[t]{2}{*}{ Month } & $R_{\text {month }}=10 \cdot 0.0125 P_{\text {month }}^{1.6295}$ & $\mathrm{Wu}(1994)$ & 60.2 & 0.57 \\
\hline & $R_{\text {month }}=10 \cdot\left(0.3046 P_{\text {month }}-2.6398\right)$ & Zhou et al. (1995) & 67.3 & 0.35 \\
\hline \multirow[t]{4}{*}{ Year } & $R_{\text {year }}=1.77 P_{5-10}-133.03$ & Sun et al. (1990) & 86.7 & -0.63 \\
\hline & $R_{\text {year }}=9.8 \cdot 0.272\left(P_{\text {year }}\left(P_{60}\right)_{\text {year }} / 100\right)^{1.205}$ & Wang et al. (1995) & 33.9 & 0.79 \\
\hline & $R_{\text {year }}=9.8 \cdot 1.67\left(P_{\geq 10 \text { year }}\left(P_{60}\right)_{\text {year }} / 100\right)^{0.953}$ & Wang et al. (1995) & 20.3 & 0.86 \\
\hline & $R_{\text {year }}=0.0534 P_{\text {year }}^{1.65 \overline{4} 8}$ & Zhang and Fu (2003) & 44.4 & 0.10 \\
\hline \multirow{6}{*}{$\begin{array}{l}\text { Average } \\
\text { annual }\end{array}$} & $R_{\text {annual }}=9.8 \cdot 0.009 \mathrm{P}_{\text {annual }}^{0.564} \cdot \overline{\left(P_{60}\right)_{\text {annual }}} 1.155 \cdot \overline{\left(P_{1440}\right)_{\text {annual }}} 0.560$ & Wang et al. (1995) & 21.2 & 0.78 \\
\hline & $R_{\text {annual }}=9.8 \cdot 0.0244 \mathrm{P}_{\geq 10 \text { annual }}^{0.551} \cdot{\overline{\left(P_{60}\right)_{\text {annual }}}}^{1.175} \cdot{\overline{\left(P_{1440}\right)_{\text {annual }}}}^{0.376}$ & Wang et al. (1995) & 15.8 & 0.82 \\
\hline & $R_{\text {annual }}=9.8 \cdot 2.135\left(\mathrm{P}_{\geq 10 \text { annual }} \cdot\left(P_{60}\right)_{\text {annual }} / 100\right)^{0.919}$ & Wang et al. (1995) & 13.2 & 0.91 \\
\hline & $R_{\text {annual }}=0.1833 F_{F}^{1.9957}, F_{F}=\frac{1}{N} \sum_{i=1}^{N} \frac{\sum_{j=1} P_{i, j}^{2}}{\sum_{j=1}^{12} P_{i, j}}$ & Zhang and Fu (2003) & 55.9 & -1.21 \\
\hline & $R_{\text {annual }}=0.3589 F^{1.9462}, F=\left(\sum_{j=1}^{12} P_{\text {ave_month } \_j}^{2}\right) / P_{\text {annual }}$ & Zhang and Fu (2003) & 60.8 & -2.11 \\
\hline & $R_{\text {annual }}=0.0668 P_{\text {annual }}^{1.6266}$ & Zhang and $\mathrm{Fu}(2003)$ & 34.6 & -0.03 \\
\hline
\end{tabular}

${ }^{1} \mathrm{MAPE}_{\mathrm{sym}}(\%)$ is the symmetric mean absolute percentage error values for all the data across validation stations for $R$ with timescales intended for the model. ${ }^{2}$ ME is the Nash-Sutcliffe model efficiency coefficient for all the data across validation stations for $R$ with timescales intended for the model. 
Models by Wang (1987) and Wang et al. (1995) utilized $\left(\mathrm{m} \mathrm{tm} \mathrm{ha}^{-1} \mathrm{~h}^{-1} \mathrm{a}^{-1}\right)$ as the units of $R$ for comparison. A conversion factor of 9.8 was multiplied to convert $R$ to $\left(\mathrm{MJ} \mathrm{mm} \mathrm{ha} \mathrm{h}^{-1} \mathrm{~h}^{-1} \mathrm{a}^{-1}\right)$. Later, models by Wu (1994) and Zhou et al. (1995) utilized $\left(\mathrm{J} \mathrm{m} \mathrm{m}^{-2} \mathrm{~h}^{-1} \mathrm{a}^{-1}\right)$. Their conversion factor, 10, was multiplied to convert $\left(\mathrm{J} \mathrm{m} \mathrm{m}^{-2} \mathrm{~h}^{-1} \mathrm{a}^{-1}\right)$ to $\left(\mathrm{MJ} \mathrm{mm} \mathrm{ha} \mathrm{h}^{-1} \mathrm{~h}^{-1} \mathrm{a}^{-1}\right)$.

\subsection{Assessment of the models}

After the 21 models in Table 2 were calibrated with the data from the 11 calibration stations, the performance for these models was assessed and compared with the performance of the previously published models listed in Table 3 using data from the seven validation stations. Symmetric mean absolute percentage error $\left(\mathrm{MAPE}_{\mathrm{sym}}\right)$ and the Nash-Sutcliffe model efficiency coefficient (ME) were utilized to reflect the deviation of the calculated values from the observation data. $\mathrm{MAPE}_{\text {sym }}$ is considered to be superior to MAPE, since it corrects the problem of MAPE's asymmetry and the possible influence by outliers (Makridakis and Hibon, 1995). MAPE $_{\text {sym }}$ was calculated as follows (Armstrong, 1985):

$\mathrm{MAPE}_{\mathrm{sym}}=\frac{100}{m} \sum_{k=1}^{m}\left|\frac{R_{\mathrm{sim}}(k)-R_{\mathrm{obs}}(k)}{\left(R_{\mathrm{sim}}(k)+R_{\mathrm{obs}}(k)\right) / 2}\right|$,

where $R_{\mathrm{obs}}$ is the measured rainfall erosivity for the $k$ th period of time, such as month, year, or annual, based on $1 \mathrm{~min}$ resolution rainfall data. $R_{\text {sim }}$ is the estimated value for the same period using equations in Tables 2 or 3 .

ME was calculated as follows (Nash and Sutcliffe, 1970):

$$
\mathrm{ME}=1-\frac{\sum_{k}^{m}\left[R_{\mathrm{sim}}(k)-R_{\mathrm{obs}}(k)\right]^{2}}{\sum_{k}^{m}\left[R_{\mathrm{obs}}(k)-\overline{R_{\mathrm{obs}}}(k)\right]^{2}} .
$$

ME compares the measured values to a perfect fit (1:1 line). Hence, ME is a combined measure of linearity, bias, and relative differences between the measured and predicted values. The maximum possible value for ME is 1 . The greater the value the better the model fit. An efficiency of $\mathrm{ME}<0$ indicates the single value (the mean) for the measured data's mean is a better predictor of the data than the model.

$\mathrm{MAPE}_{\mathrm{sym}}$ and ME were calculated based on all the data for the seven validation stations. Individual values for all stations were also determined.

\section{Results and discussion}

\subsection{Basic data results}

Average annual rainfall ranged from 449.7 to $1728.1 \mathrm{~mm}$, and average annual erosivity varied from 781.9 to $8258.5 \mathrm{MJ} \mathrm{mm} \mathrm{ha}^{-1} \mathrm{~h}^{-1} \mathrm{yr}^{-1}$ (Table 1). A total of 11801 erosive events were used in the study. The eleven stations had 6376 erosive events, which were used to calibrate the models, and the seven validation stations had 5425 erosive events.

\subsection{Validation and calibration for the new models}

Parameters, $\mathrm{MAPE}_{\mathrm{sym}}$, ME, and coefficients of determination, $R^{2}$, for calibration models are shown in Table 4 . The model Event IV, with a combination of event rainfall amount $P_{\text {event }}$ and $I_{30}$, when $I_{30}$ was divided into two categories, with a threshold of $15 \mathrm{~mm} \mathrm{~h}^{-1}$, performed slightly better in terms of the MAPE $\mathrm{sym}_{\text {sym }}$ value than did Event II, which used the same variables but did not separate the rainfall events by intensity. The performance of Daily I with daily rainfall amount and $\left(I_{10}\right)_{\text {daily }}$ was similar to that for Event I with event rainfall amount and $I_{10}$.

Using only total rainfall amount as input, the models for month, year, and average monthly scales were statistically significant, with determination coefficients $R^{2}$ greater than 0.66 (Table 4 and Fig. 2). However, their capabilities in predicting erosivity were limited based on the ME values (Table 4). Data from Tengchong and Xichang, located in the southwestern part of China, were in part responsible for these low ME values. Table 5 shows the individual values of $\mathrm{MAPE}_{\text {sym }}$ and ME for the seven validation stations, with the average of each using all the stations and using only the five without Tengchong and Xichang. Results were much better without those two stations. The model Annual I, which use only average annual precipitation values, performed reasonably well, considering that the only input required was annual average precipitation (Table 4). If other information is available, other models performed better, but Annual I may be used if only average annual precipitation is available at a location.

In general, we found that the finer the temporal resolution of the rainfall input data, the better the models performed for a given erosivity timescale. Models that used some expression of maximum daily rainfall amount (Month III, Year III, Average Monthly III, Average Monthly V, Annual III, and Annual Model V) predicted the $R$ factor better than those models with only total rainfall amount as input (Table 4), for a specific timescale. Models based on rainfall amount and maximum contiguous $60 \mathrm{~min}$ rainfall amounts (Month II, Year II, Average Monthly II, Average Monthly IV, Annual II, and Annual IV) generally performed better than corresponding models with rainfall amount and maximum daily rainfall amount (Month III, Year III, Average Monthly III, Average Monthly V, Annual III), except for Annual Model $\mathrm{V}$, which performed well. The reason for that may be due to the fact that maximum contiguous 60 min rainfall amounts may have been more highly correlated with maximum contiguous 30 min intensity in an event as compared to just the maximum daily rainfall amount. The only annual average model that did not perform well was Annual III, which uti- 
Table 4. Models calibrated in this study and their prediction capabilities determined using the validation stations - the symmetric mean absolute percentage errors, MAPE $_{\text {sym }}$, and Nash-Sutcliffe model efficiencies, ME.

\begin{tabular}{|c|c|c|c|c|}
\hline Model codes & Models 1 & $R^{2}$ & MAPE $_{\text {sym }}(\%)$ & ME \\
\hline Event I & $E I_{30}=0.1547 P_{\text {event }} I_{10}$ & 0.92 & 34.5 & 0.91 \\
\hline Event II & $E I_{30}=0.2372 P_{\text {event }} I_{30}$ & 0.98 & 29.3 & 0.98 \\
\hline Event III & $E I_{30}=0.3320 P_{\text {event }} I_{60}$ & 0.94 & 35.8 & 0.96 \\
\hline Event IV & 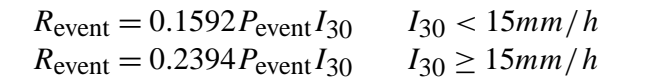 & 0.97 & 13.9 & 0.98 \\
\hline Daily I & $R_{\text {day }}=0.1661 P_{\text {day }}\left(I_{10}\right)_{\text {day }}$ & 0.92 & 38.4 & 0.91 \\
\hline Month I & $R_{\text {month }}=0.1575 P_{\text {month }}^{1.6670}$ & 0.66 & 69.5 & 0.48 \\
\hline Month II & $R_{\text {month }}=0.1862 P_{\text {month }}\left(P_{60}\right)_{\text {month }}$ & 0.85 & 36.0 & 0.88 \\
\hline Month III & $R_{\text {month }}=0.0770 P_{\text {month }}\left(P_{1440}\right)_{\text {month }}$ & 0.65 & 55.2 & 0.69 \\
\hline Year I & $R_{\text {year }}=0.5115 P_{\text {year }}^{1.3163}$ & 0.70 & 38.1 & 0.48 \\
\hline Year II & $R_{\text {year }}=0.1101 P_{\text {year }}\left(P_{60}\right)_{\text {year }}$ & 0.80 & 20.9 & 0.84 \\
\hline Year III & $R_{\text {year }}=0.0502 P_{\text {year }}\left(P_{1440}\right)_{\text {year }}$ & 0.54 & 28.9 & 0.59 \\
\hline $\begin{array}{l}\text { Average } \\
\text { Monthly } \\
\text { I }\end{array}$ & $R_{\text {ave_month }}=0.0755 P_{\text {ave_month }}^{1.8430}$ & 0.89 & 44.7 & 0.17 \\
\hline $\begin{array}{l}\text { Average } \\
\text { Monthly } \\
\text { II }\end{array}$ & $R_{\text {ave_month }}=0.0877 P_{\text {ave_month }}\left(P_{60}\right)_{\text {month_max }}$ & 0.94 & 23.5 & 0.88 \\
\hline $\begin{array}{l}\text { Average } \\
\text { Monthly } \\
\text { III }\end{array}$ & $R_{\text {ave_month }}=0.0410 P_{\text {ave_month }}\left(P_{1440}\right)_{\text {month_max }}$ & 0.87 & 30.1 & 0.73 \\
\hline $\begin{array}{l}\text { Average } \\
\text { Monthly } \\
\text { IV }\end{array}$ & $R_{\text {ave } \_ \text {month }}=0.2240 P_{\text {ave } \_ \text {month }} \overline{\left(P_{60}\right)_{\text {month }}}$ & 0.98 & 22.9 & 0.88 \\
\hline $\begin{array}{l}\text { Average } \\
\text { Monthly } \\
\text { V }\end{array}$ & $R_{\text {ave_month }}=0.1082 P_{\text {ave_month }} \overline{\left(P_{1440}\right)_{\text {month }}}$ & 0.94 & 31.4 & 0.79 \\
\hline Annual I & $R_{\text {annual }}=1.2718 P_{\text {annual }}^{1.1801}$ & 0.89 & 25.6 & 0.63 \\
\hline Annual II & $R_{\text {annual }}=0.0584 P_{\text {annual }}\left(P_{60}\right)_{\text {year_max }}$ & 0.92 & 15.4 & 0.91 \\
\hline Annual III & $R_{\text {annual }}=0.0253 P_{\text {annual }}\left(P_{1440}\right)_{\text {year_max }}$ & 0.92 & 22.5 & -0.44 \\
\hline Annual IV & $R_{\text {annual }}=0.1058 P_{\text {annual }} \overline{\left(P_{60}\right)_{\text {annual }}}$ & 0.94 & 17.0 & 0.88 \\
\hline Annual V & $R_{\text {annual }}=0.0492 P_{\text {annual }} \overline{\left(P_{1440}\right)_{\text {annual }}}$ & 0.92 & 18.2 & 0.91 \\
\hline
\end{tabular}

lized $\left(P_{1440}\right)_{\text {year_max }}$, the maximum of $\left(P_{1440}\right)_{\text {year values for }}$ each year over the entire period of record.

Tables 3 and 4 show the models only evaluated for the erosivity temporal scale that corresponds to the input data resolution. For example, the event-based models are only evaluated on the basis of events modeled. We also evaluated the models at the aggregate scale. For example, $E I_{30}$ estimated from event-based models were summed up to month and year values, in order to evaluate if fine temporal resolution data also improve the accuracy of aggregate erosivity measures (Table 6). Two important facts emerge. First, when the models are applied at the aggregated scale their predictions get better. Secondly, the models that use fine resolution of input data predict better for the same erosivity timescale compared to models using coarser resolution input data. This has important implications for model applications.

\subsection{Seasonal variations of erosivity}

Taking Tonghe and Tengchong as examples, it was found that Month II generated better results than Month III, which performed better than Month I, in estimating seasonal and yearly variations (Figs. 3a, b and 4a, b). Correspondingly, seasonal variations by Average Monthly II were closer to observations as compared to those by Average Monthly III and Average Monthly I (Fig. 3c and d). Year II and Year III produced better simulations of yearly variations compared with Year I, especially for the Tengchong station (Fig. 4c, d). 
(a) Month I
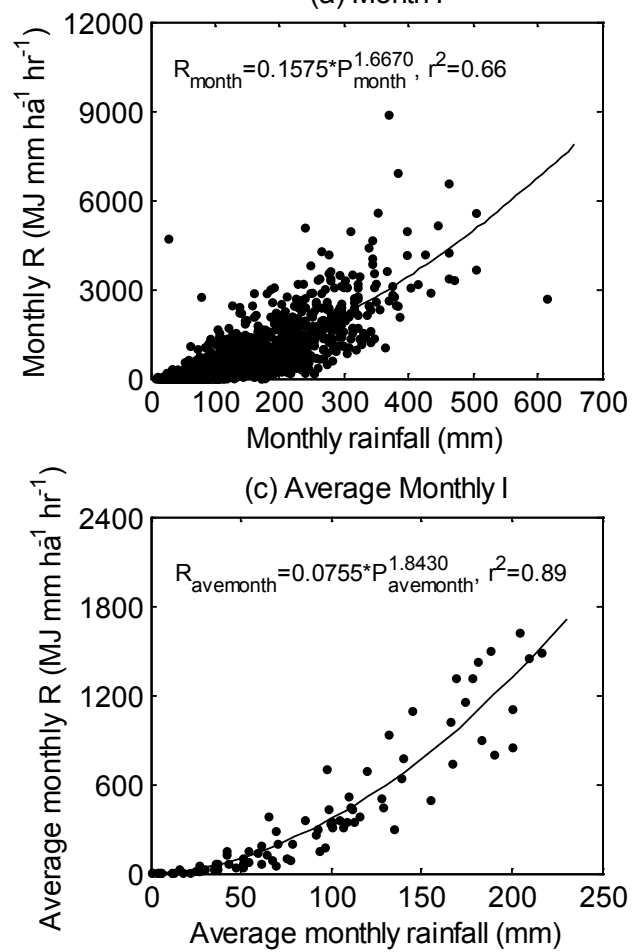

(b) Year I

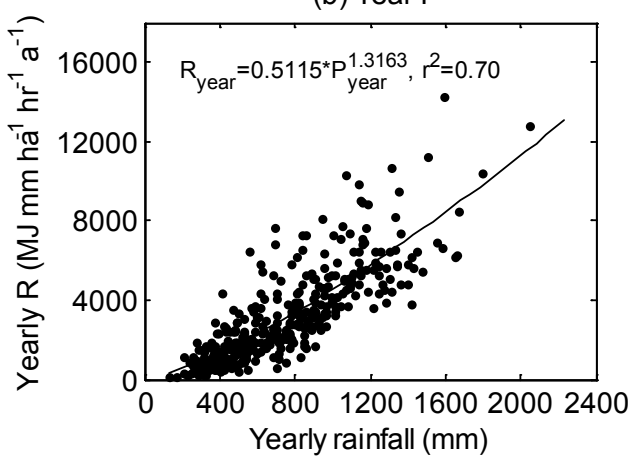

(d) Annual I

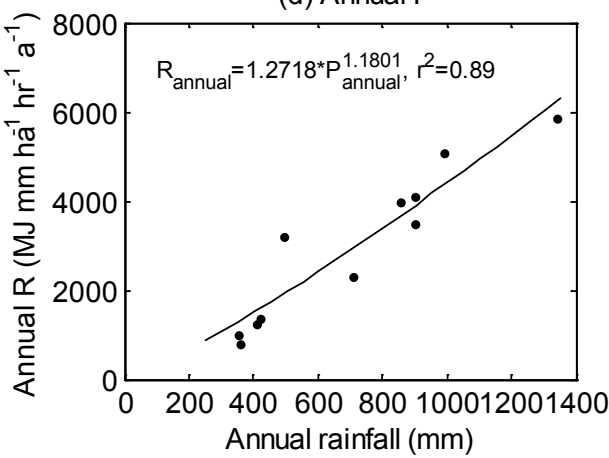

Figure 2. Scatterplots for power-law models using rainfall amount: (a) Month I, (b) Year I, (c) Average Monthly I, and (d) Annual I, based on the 11 calibration stations.

Table 5. Validation station-averaged symmetric mean absolute percentage errors (MAPE $\left.\mathrm{sym}_{\mathrm{m}}\right)$ and Nash-Sutcliffe model efficiency coefficients (ME) for $R_{\text {month }}$ by Month I, $R_{\text {year }}$ by Year I and $R_{\text {ave_month }}$ by Average Monthly I models for seven validation stations and statistics on event rainfall amount and event $E I_{30}$.

\begin{tabular}{|c|c|c|c|c|c|c|c|c|}
\hline \multirow[t]{2}{*}{ Station name } & \multicolumn{2}{|c|}{$R_{\text {month by Month I }}$} & \multicolumn{2}{|c|}{$R_{\text {year by Year I }}$} & \multicolumn{2}{|c|}{$\begin{array}{c}R_{\text {ave_month by Average }} \\
\text { Monthly I }\end{array}$} & \multirow{2}{*}{$\begin{array}{r}\text { Percent of } \\
\text { erosive } \\
\text { amount }(\%)\end{array}$} & \multirow[t]{2}{*}{$E I_{30} / \mathrm{P}$} \\
\hline & MAPE $_{\text {sym }}$ & $\mathrm{ME}$ & MAPE $_{\text {sym }}$ & ME & MAPE $_{\text {sym }}$ & ME & & \\
\hline Tonghe & 70.2 & 0.73 & 30.9 & 0.47 & 29.5 & 0.93 & 71.2 & 4.8 \\
\hline Yangcheng & 65.5 & 0.31 & 27.1 & 0.55 & 16.4 & 0.96 & 81.7 & 4.2 \\
\hline Miyun & 52.0 & 0.71 & 45.1 & -0.06 & 37.6 & 0.88 & 82.8 & 7.8 \\
\hline Xichang & 77.5 & 0.47 & 45.4 & -0.15 & 57.2 & 0.09 & 76.9 & 4.1 \\
\hline Huangshi & 70.1 & 0.65 & 24.5 & 0.63 & 46.1 & 0.73 & 86.5 & 5.7 \\
\hline Tengchong & 83.4 & -2.01 & 66.6 & -7.51 & 68.3 & -6.98 & 71.9 & 3.6 \\
\hline Changting & 52.0 & 0.54 & 20.9 & 0.26 & 35.2 & 0.30 & 88.4 & 6.1 \\
\hline Mean $^{1}$ & 67.2 & 0.20 & 37.2 & -0.83 & 41.5 & -0.44 & 79.9 & 5.2 \\
\hline Mean $^{2}$ & 62.0 & 0.59 & 29.7 & 0.37 & 38.7 & 0.60 & 82.1 & 5.7 \\
\hline
\end{tabular}

${ }^{1}$ Averaged value for seven validation stations. ${ }^{2}$ Averaged value for five validation stations except Xichang and Tengchong.

Seasonal variations by monthly and average monthly models (Fig. 3) and yearly variations by month and year models (Fig. 4) were demonstrated using Tonghe and Tengchong stations. Month I and Average Monthly I captured the general seasonal pattern for the Tonghe station (Fig. 3a and c), but the simulated peak value of monthly $R$ was in July for the Tengchong station, which was not consistent with observation.
Month I and Year I captured the general year-to-year pattern for the Tonghe station (Fig. 4a and c), but they overestimated yearly erosivity for the Tengchong station (Fig. $4 b$ and d). Month I and Year I also overestimated the yearly erosivity for the Xichang station. The reason for the overestimation for the Tengchong and Xichang stations was mainly due to two aspects: (1) the percentages of erosive rainfall amount to to- 
Table 6. MAPE $\mathrm{sym}_{\mathrm{s}}$ for the models when used to estimate longer timescales of erosivity.

\begin{tabular}{|c|c|c|c|c|c|c|c|}
\hline $\begin{array}{l}\text { Model } \\
\text { codes }\end{array}$ & Models & & $\begin{array}{r}\text { Event and } \\
\text { Daily }\end{array}$ & Month & $\begin{array}{l}\text { Avg. } \\
\text { monthly }\end{array}$ & Year & Annual \\
\hline Event I & \multicolumn{2}{|l|}{$E I_{30}=0.1547 P_{\text {event }} I_{10}$} & 34.5 & 29.0 & 20.4 & 16.4 & 12.0 \\
\hline Event II & \multicolumn{2}{|l|}{$E I_{30}=0.2372 P_{\text {event }} I_{30}$} & 29.3 & 24.2 & 16.0 & 11.4 & 9.1 \\
\hline Event III & \multicolumn{2}{|l|}{$E I_{30}=0.3320 P_{\text {event }} I_{60}$} & 35.8 & 28.5 & 15.1 & 10.8 & 6.2 \\
\hline Event IV & $\begin{array}{l}R_{\text {event }}=0.1592 P_{\text {event }} I_{30} \\
R_{\text {event }}=0.2394 P_{\text {event }} I_{30}\end{array}$ & $\begin{array}{l}I_{30}<15 \mathrm{mmh}^{-1} \\
I_{30} \geq 15 \mathrm{~mm} \mathrm{~h}^{-1}\end{array}$ & 13.9 & 11.0 & 7.0 & 6.4 & 4.7 \\
\hline Daily I & \multicolumn{2}{|l|}{$R_{\text {day }}=0.1661 P_{\text {day }}\left(I_{10}\right)_{\text {day }}$} & 38.4 & 29.2 & 19.6 & 16.2 & 11.7 \\
\hline Month I & \multicolumn{2}{|l|}{$R_{\text {month }}=0.1575 P_{\text {month }}^{1.6670}$} & & 69.5 & 46.7 & 39.4 & 28.7 \\
\hline Month II & \multicolumn{2}{|c|}{$R_{\text {month }}=0.1862 P_{\text {month }}\left(P_{60}\right)_{\text {month }}$} & & 36.0 & 19.9 & 18.6 & 13.1 \\
\hline Month III & \multirow{2}{*}{\multicolumn{2}{|c|}{$\begin{array}{l}R_{\text {month }}=0.0770 P_{\text {month }}\left(P_{1440}\right)_{\text {month }} \\
R_{\text {mor }}=0.315 P^{1.3163}\end{array}$}} & & 55.2 & 26.7 & 24.8 & 12.3 \\
\hline Year I & & \multicolumn{2}{|c|}{$R_{\text {year }}=0.5115 P_{\text {year }}^{1.3163}$} & & & 38.1 & 23.5 \\
\hline Year II & \multicolumn{3}{|l|}{$R_{\text {year }}=0.1101 P_{\text {year }}\left(P_{60}\right)_{\text {year }}$} & & & 20.9 & 14.3 \\
\hline Year III & \multicolumn{2}{|c|}{$R_{\text {year }}=0.0502 P_{\text {year }}\left(P_{1440}\right)_{\text {year }}$} & & & & 28.8 & 17.3 \\
\hline
\end{tabular}

(a) Tonghe from month models

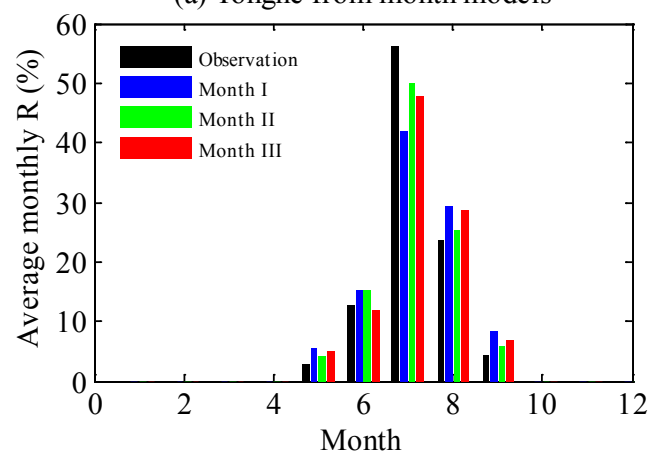

(c) Tonghe from average monthly models

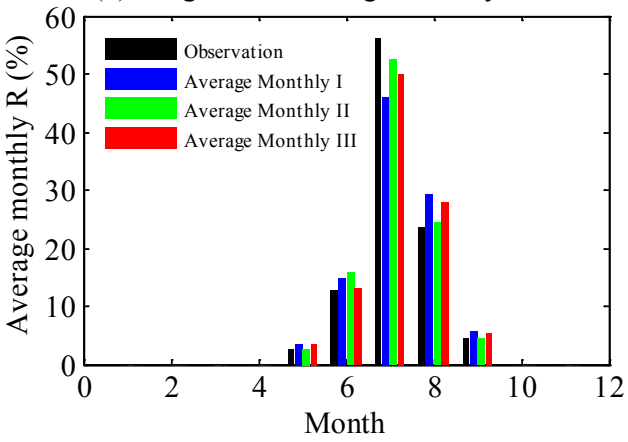

(b) Tengchong from month models

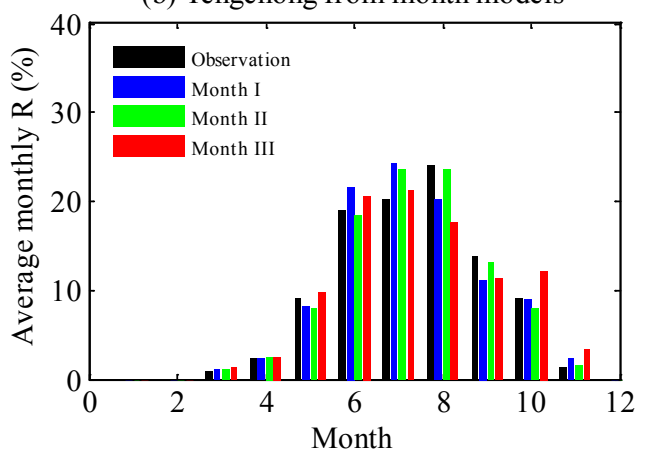

(d) Tengchong from average monthly models

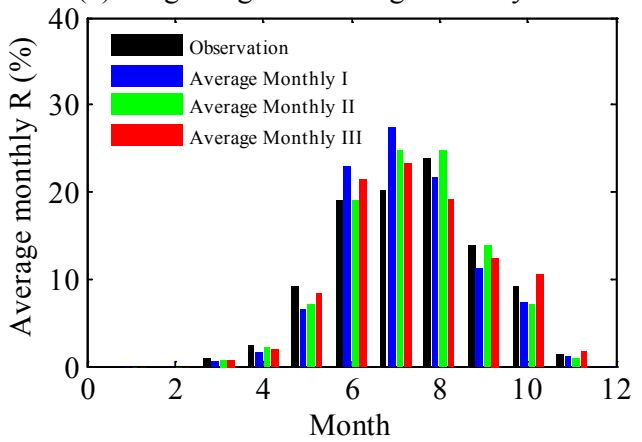

Figure 3. Comparisons of average monthly $R$ values between observation values calculated using 1 min resolution rainfall data and estimated values using month models $(\mathbf{a}, \mathbf{b})$ and average monthly models $(\mathbf{c}, \mathbf{d})$ for the Tonghe and Tengchong stations.

tal rainfall at those stations were lower $(71.9$ and $76.9 \%$, respectively), suggesting that more events occurred with small amount totals that do not generate soil loss (Table 5); and (2) the ratio for event $E I_{30}$ to event rainfall amount $P$ was lower (3.6 and 4.1, respectively), inferring that rainfall intensity and erosivity generated by per amount of rainfall were both less than that of the other stations (Table 5). This result was consistent with that of Nel et al. (2013), which demonstrated that two models using annual average rainfall and average monthly rainfall substantially overestimated annual erosivity on the west coast and the central plateau of Mauritius, which also have a large amount of non-erosive rainfall. Rainfall erosivity reflected a combined effect of rainfall amount and rainfall intensity. Therefore, it was reasonable that rainfall amount only explained part of rainfall erosivity variation at these stations. 
(a) Tonghe from month models

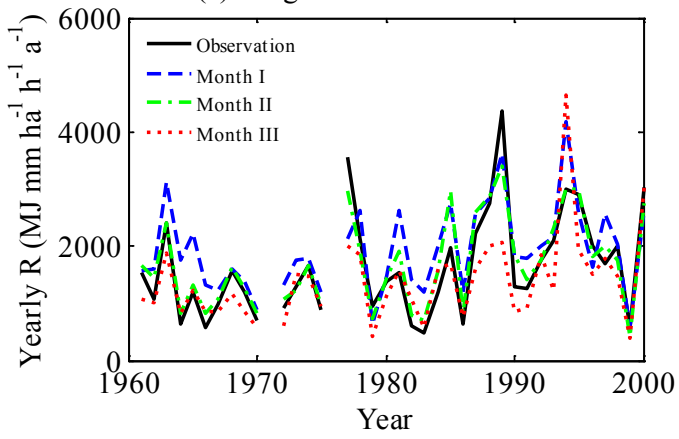

(c) Tonghe from year models

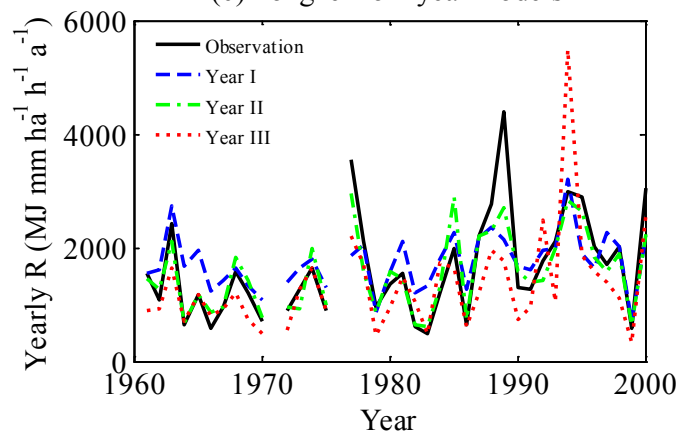

(b) Tengchong from month models

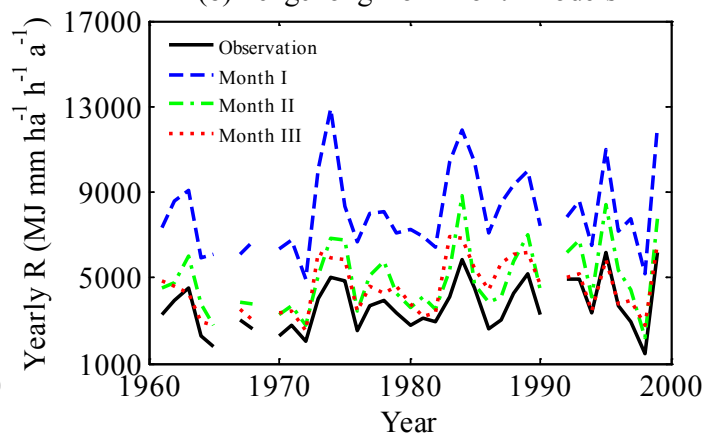

(d) Tengchong from year models

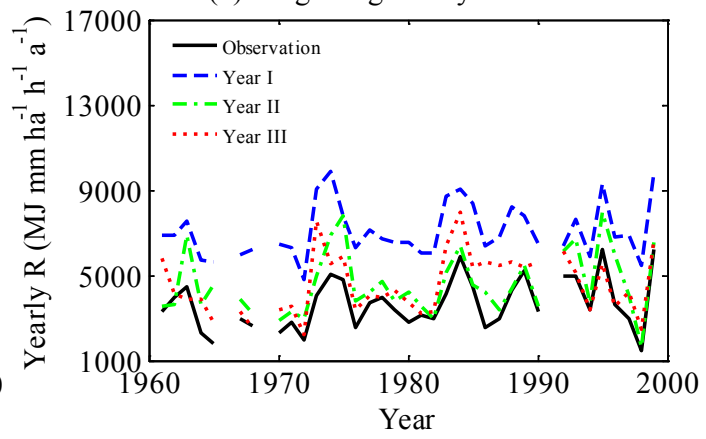

Figure 4. Comparison of yearly $R$ values between observation values calculated using 1 min resolution rainfall data and estimated values using month models $(\mathbf{a}, \mathbf{b})$ and year models $(\mathbf{c}, \mathbf{d})$ for the Tonghe and Tengchong stations. The years without marks were ineffective years.

\subsection{Evaluation of models from previous research with current models}

Generally speaking, the finer the resolution of input data for models, the better was the performance of the model for estimating at the same temporal erosivity scale. For example, the models with daily rainfall amount and daily maximum 60 or 10 min amount as inputs performed better than models with only daily rainfall amount as input. Similarly, results from models with maximum 60 min rainfall amount (Month II, Year II, Average Monthly IV, and Annual IV) were generally better than those with maximum daily rainfall amount (Month III, Year III, Average Monthly V, and Annual V; Fig. 5).

Wang et al. (1995) used a combination of event rainfall amount $P_{\text {event }}$ and $I_{10}$ for event-scale models. The model using the $I_{10}$ data was divided into two categories, with a threshold of $10 \mathrm{~mm} \mathrm{~h}^{-1}$, performed best among the four models compared (Table 3 ). That model had similar performance with Event IV in this study (Table 4), which also divided the data by a rainfall-intensity threshold.

There were three kinds of daily-scale models, according to the number and type of inputs required. Two models used daily rainfall amount (Zhang et al., 2002b; Xie et al., 2015), two models used daily rainfall amount and daily maximum 10 min intensity (Xie et al., 2001 and Daily I), and one model used daily rainfall amount and daily maximum $60 \mathrm{~min}$ inten- sity (Xie et al., 2015). The model with daily rainfall amount as input in Xie et al. (2015) performed better than that of Zhang et al. (2002b) (Table 3). Daily I, which used daily rainfall amount and daily maximum $10 \mathrm{~min}$ intensity as inputs in this study, performed better than the model in Xie et al. (2001). Models with an additional daily 10 or 60 min intensity index performed better than those with only a total rainfall amount (Tables 3 and 4).

There were generally four groups of models for month, year, average monthly, and annual-scale models. The first group used linear regression (Sun et al., 1990; Wu, 1994; Zhou et al., 1995) or a power-law function (Zhang and $\mathrm{Fu}$, 2003; Month I, Year I, Average Monthly I, and Annual I) with only rainfall amount as input, so that the data required were relatively easy to collect. Models by Sun et al. (1990), Wu (1994) and Zhou et al. (1995), when they were used to estimate the monthly scale of $R$, had MAPE $\mathrm{sym}_{\mathrm{sm}}$ values of 86.7, 60.2 and $67.3 \%$ and $\mathrm{ME}$ of $-0.63,0.57$ and 0.35 , respectively (Table 3 ). When they were used to estimate annual scale of $R$, there was a tendency of underestimation, especially for the stations with larger erosivity (Fig. 5a, b). Four models by Zhang and Fu (2003) overestimated the $R$

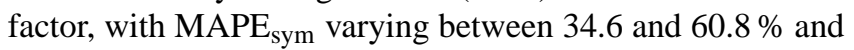
ME varying between -2.11 and 0.10 (Table 3, Fig. 5), which suggested the models' abilities were limited. Two models by Zhang and Fu (2003) using the modified Fournier index generated poorer results than the model by Zhang and Fu (2003) 

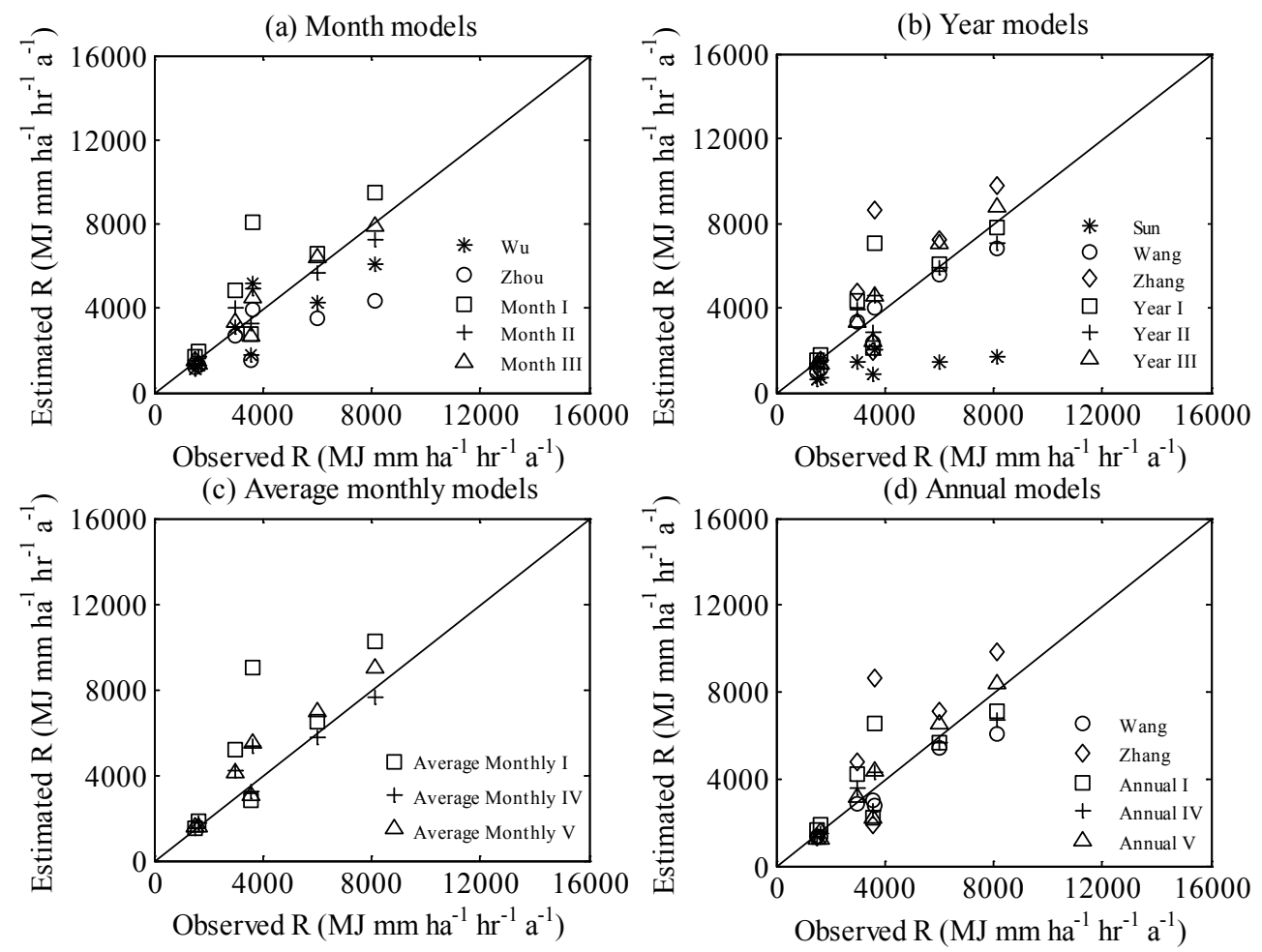

Figure 5. Comparisons of the estimated $R$ factor value calculated based on (a) month, (b) year, (c) average monthly, and (d) average annual models using $1 \mathrm{~min}$ resolution data for the seven independent validation stations. Month models included models in Wu (1994), Zhou et al. (1995), and Month I, II, and III from this study. Year models included models from Sun et al. (1990), Wang et al. (1995; the one with MAPE $_{\text {sym }}$ of $20.3 \%$ ), Zhang and Fu (2003), and Year I, II, and III from this study. Average monthly models included models from Average Monthly I, II, and III from this study. Average annual models included models from Wang et al. (1995; the one with MAPE $\mathrm{sym}_{\mathrm{s}}$ of $13.2 \%$ ),

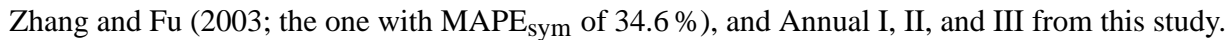

using average annual rainfall as input (Table 3), which was consistent with the findings of Yu and Rosewell (1996). The power-law models in this study, including Month I, Year I, Average Monthly I, and Annual I, tended to overestimate the $R$ factor for the stations with larger erosivity (Fig. 5).

The second group of models (Wang et al., 1995; Month II, Year II, Average Monthly IV, Annual IV) used linear regression with rainfall amount (total rainfall or total rainfall with daily rainfall no less than $10 \mathrm{~mm}$ ) and maximum $60 \mathrm{~min}$ rainfall as inputs. All these seven models generated statistically significant results, with MAPE $_{\mathrm{sym}}$ for $R$ with timescale intended for the model ranging from 13.2 to $36.0 \%$ and $\mathrm{ME}$ from 0.79 to 0.91 (Tables 3 and 4; Fig. 5).

The third group used linear regression with rainfall amount and maximum daily rainfall as inputs (Month III, Year III, Average Monthly V, Annual V), which generated reasonable results (Table 4) and a slightly overestimated annual $R$ (Fig. 5). Overall they did not perform as well as did the models in the second group (Table 4).

The fourth group (Wang et al., 1995) used a combination of three indices, including rainfall amount, maximum 60 min rainfall amount, and maximum daily rainfall amount as inputs and generated good simulation results; however, there was no improvement compared with the two models by Wang et al. (1995) in the second group (Table 3).

\subsection{Applications and recommendations}

The results of this study provide a multitude of options for dealing with the problem of variations in available temporal resolutions of rainfall data from across the world for developing erosivity maps and databases. We present a series of 21 potential equations for use in estimating erosivity at timescales from event to average annual using input data resolution ranging from maximum $10 \mathrm{~min}$ rainfall intensity to average annual rainfall amount. Of the 21 equations we can recommend the use of 17. Equations Month I, Year I, and Average Monthly I, which use only total rainfall amounts for the respective timescales, all had low ME values and poor prediction capability (Table 4). Annual III, which is a linear function of average annual rainfall and the maximum daily precipitation over the recording period, performed very poorly, with a negative ME value (Table 4).

We found that using finer resolution data input produced better predictions of erosivity at a given output timescale. An exception was for the event-based models, where using $I_{30}$ 
gave slightly better results than using $I_{60}$ or $I_{10}$. However, we also found that using equations with the finest data resolution possible, and aggregating or summing results for finer erosivity timescales, gave the best results (Table 6). In other words, if one were interested in average annual erosivity, but had rainfall data available for using the Daily I model, then results are better using the Daily I model and summing results over the period of data record rather than using Annual $\mathrm{I}-\mathrm{V}$ models. It is also evident that predictions of erosivity using Daily I improve as the timescale increases. In other words, the predictions of average annual erosivity calculated by summing the daily values from Daily I give a higher level of fit than when using Daily I to estimate daily erosivity (Table 6).

Models in this study performed better or similar to models from previous research given the same rainfall data inputs based on these independent validation data (Tables 4 and 5). Models from previous research had higher symmetric mean absolute percentage errors, MAPEsym, and lower Nash-Sutcliffe model efficiencies, ME, with the exception of models for event, year, and average annual timescales by Wang et al. (1995), which had similar MAPEsym and ME compared to the models in this study.

Much attention has been given to monitoring the erosion process and its controlling factors at various spatiotemporal scales (Poesen et al., 2003). Characteristics of topography and soils are usually relatively constant in the timescales of interest, whereas rainfall erosivity and vegetation vary greatly. Therefore, soil erosion monitoring work is often mainly focused on the dynamics of rainfall erosivity and vegetation rather than soil and topography (Vrieling et al, 2014). Different timescales of erosivity are required in areas with different resolutions of rainfall data availability. Models provided in this study have potential to play important roles in the soil erosion monitoring framework in terms of quantifying the temporal dynamics and changes in rainfall erosivity.

Acknowledgements. The authors would like to thank the Heilongjiang, Shanxi, Shaanxi, Beijing, Sichuan, Hubei, Fujian, and Yunnan Meteorological Bureaus for supplying rainfall data and the three anonymous reviewers for their valuable and constructive comments. This work was supported by the National Natural Science Foundation of China (no. 41301281) and the China Scholarship Council. USDA is an equal opportunity provider and employer.

Edited by: N. Romano

\section{References}

Angulo-Martínez, M. and Beguería, S.: Trends in rainfall erosivity in NE Spain at annual, seasonal and daily scales, 1955-2006, Hydrol. Earth Syst. Sci., 16, 3551-3559, doi:10.5194/hess-163551-2012, 2012.
Armstrong, J. S.: Long-range forecasting: From crystal ball to computer, 2nd Edn., Wiley, New York, 1985.

Arnoldus, H. M. J.: Methodology used to determine the maximum potential average annual soil loss due to sheet and rill erosion in Morocco, FAO Soils Bull., 34, 39-51, 1977.

Bonilla, C. A. and Vidal, K. L.: Rainfall erosivity in Central Chile, J. Hydrol., 410, 126-133, 2011.

Brown, L. C. and Foster, G. R.: Storm erosivity using idealized intensity distributions, Trans. ASABE., 30, 379-386, 1987.

Capolongo, D., Diodato, N., Mannaerts, C. M., and Piccarreta, M.: Analyzing temporal changes in climate erosivity using a simplified rainfall erosivity model in Basilicata (southern Italy), J. Hydrol., 356, 119-130, 2008.

China Meteorological Administration (CMA): Specifications for surface meteorological observation, Meteorology Publishing House, Beijing, 2003.

Fan, J., Chen, Y., Yan, D., and Guo, F.: Characteristics of rainfall erosivity based on tropical rainfall measuring mission data in Tibet, China, J. Mountain Sci., 10, 1008-1017, 2013.

Ferro, V., Porto, P., and Yu, B.: A comparative study of rainfall erosivity estimation for southern Italy and southeastern Australia, Hydrolog. Sci. J., 44, 3-24, 1999.

Flanagan, D. C., Meyer, C. R., Yu, B., Scheele, D. L.: Evaluation and enhancement of the CLIGEN weather generator, in: Proceedings-Soil Erosion Research for the 21st Century, edited by: Ascough II, J. C. and Flanagan, D. C., American Society of Agricultural Engineers, St. Joeseph, 107-110, 2001.

Foster, G. R.: User's Reference Guide: Revised Universal Soil Loss Equation (RUSLE2), US Department of Agriculture, Agricultural Research Service, Washington DC, 2004.

Fournier, F.: Climate et erosion; la relation entre lerosion du sol par leau et les precipitations atmospheriques, Universitaires de France, Paris, 1960.

Larionov, G. A.: Erosion and Wind Blown Soil. Moscow State University Press, Moscow, 1993.

Laws, O. J. and Parsons, D. A.: The relation of drop size to intensity. Trans. AGU, 24, 452-460, 1943.

Liu, B. Y., Zhang, K. L., and Xie, Y.: An empirical soil loss equation. in: Proceedings-Process of soil erosion and its environment effect (Vol. II), 12th international soil conservation organization conference, Tsinghua University Press, Beijing, 21-25, 2002.

Liu, B. Y., Guo, S. Y., Li, Z. G., Xie, Y., Zhang, K. L., and Liu, X. C.: Water erosion sample survey in China, Soil Water Conserv. China, 10, 26-34, 2013.

Lo, A., EI-Swaify, S. A., Dangler, E. W., and Shinshiro, L.: Effectiveness of $E_{30}$ as an erosivity index in Hawaii, in: Soil Erosion and Conservation, edited by: EI-Swaify, S. A., Moldenhauer, W. C., and Lo, A., Soil Conservation Society of America, Ankeny, 384-392, 1985.

Ma, X., He, Y. D., Xu, J. C., Noordwijk, M. V., and Lu, X. X.: Spatial and temporal variation in rainfall erosivity in a Himalayan watershed. Catena, 121, 248-259, 2014.

Makridakis, S. and Hibon, M.: Evaluating accuracy (or error) measures. Working paper, INSEAD, Fontainebleau, France, 1995.

McGregor, K. C. and Mutchler, C. K.: Status of the R factor in north Mississippi, in: Soil erosion: prediction and control. Soil and Water Conservation Society, Ankeny, IA, 135-142, 1976. 
McGregor, K. C., Bingner, R. L., Bowie, A. J., and Foster, G. R.: Erosivity index values for northern Mississippi, Trans. ASABE., 38, 1039-1047, 1995.

Nash, J. E. and Sutcliffe, J. V.: River flow forecasting through conceptual models, Part 1: A discussion of principles, J. Hydrol., 10, 282-290, 1970.

Nearing, M. A. and Bradford, J. M.: Single waterdrop splash detachment and mechanical properties of soils, Soil Sci. Soc. Am. J., 49, 547-552, 1985.

Nel, W., Anderson, R. L., Sumner, P. D., Boojhawon, R., Rughooputh, S. D. D. V., and Dunputh, B. H. J.: Temporal sensitivity analysis of erosivity estimations in a high rainfall tropical island environment, Geogr. Ann. A, 95, 337-343, 2013.

Nicks, A. D. and Lane, L. J.: Weather Generator, in: USDAWater Erosion Prediction project: Hillslope profile and watershed model documentation, edited by: Flanagan, D. C. and Nearing, M. A., NSERL Report No. 10. USDA-ARS National Soil Erosion Research Laboratory, West Lafayette, IN, 2.1-2.22, 1995.

Oliveira, P. T. S., Wendland, E., and Nearing, M. A.: Rainfall erosivity in Brazil: A review, Catena, 100, 139-147, 2012.

Panagos, P., Ballabio, C., Borrelli, P., Meusburger, K., Klikc, A., Rousseva, S., Perčec Tadić., M., Michaelides, S., Hrabalíková, M., Olsen, P., Aalto, J., Lakatos, M., Rymszewicz, A., Dumitrescu, A., Beguería, S., and Alewell C.: Rainfall erosivity in Europe, Sci. Total Environ., 511, 801-814, 2015.

Poesen, J., Nachtergaele, J., Verstraeten, G., and Valentin, C.: Gully erosion and environmental change: importance and research needs, Catena, 50, 91-133, 2003.

Ramos, M. C. and Duran, B.: Assessment of rainfall erosivity and its spatial and temporal variabilities: Case study of the Penedès area (NE Spain), Catena, 123, 135-147, 2014.

Renard, K. G. and Freimund, J. R.: Using monthly precipitation data to estimate the R- factor in the revised USLE, J. Hydrol., 15, 287-306, 1994.

Renard, K. G., Foster, G. R., Weesies, G. A., McCool, D. K. and Yoder, D. C.: Predicting soil erosion by water. Agriculture Handbook 703, US Department of Agriculture, Agricultural Research Service, Washington DC, 1997.

Richardson, C. W., Foster, G. R., and Wright, D. A.: Estimation of erosion index from daily rainfall amount, T. ASAE, 26, 153-156, 1983.

Roose, E.: Erosion et ruissellement en Afrique de louest-vingt annees de mesures en petites parcelles experimentales. Pour faire face à ce problème préoccupant, I'ORSTOM et les Instituts Travaux et Documents de I'ORSTOM, No. 78, O.R.S.T.O.M, Paris, 1977.

Sadeghi, S. H. R. and Tavangar, S.: Development of stational models for estimation of rainfall erosivity factor in different timescales, Nat. Hazards, 77, 429-443, 2015.

Sadeghi, S. H. R., Moatamednia, M., and Behzadfar, M.: Spatial and Temporal Variations in the Rainfall Erosivity Factor in Iran, J. Agr. Sci. Tech., 13, 451-464, 2011.

Sanchez-Moreno, J. F., Mannaerts, C. M., and Jetten, V.: Rainfall erosivity mapping for Santiago island, Cape Verde, Geoderma, 217, 74-82, 2014.

Schwertmann, U., Vogl, W., and Kainz, M.: Bodenerosion durch Wasser, Eugen Ulmer GmbH \& Co., Stuttgart, 1990.

Seber, G. A. F. and Wild, C. J.: Nonlinear Regression. John Wiley \& Sons, Inc., Hoboken, 2003.
Snedecor, G. W. and Cochran, W. G.: Statistical Methods, 12th Edn., The Iowa State University Press, Ames, 1989.

Sun, B. P., Zhao, Y. N., and Qi, S.: Application of USLE in loessial gully hill area. Memoir of NISWC, Academia Sinica and Ministry of Water Conservancy, Yangling, 12, 50-59, 1990.

Vrieling, A., Sterk, G., and de Jong, S. M.: Satellite-based estimation of rainfall erosivity for Africa. J. Hydrol., 395, 235-241, 2010.

Vrieling, A., Hoedjes, J. C. B., and van der Velde, M.: Towards large-scale monitoring of soil erosion in Africa: Accounting for the dynamics of rainfall erosivity, Global Planet. Change, 115, 33-43, 2014.

Wang, B. M., Lu, Y. P., and Zhang, Q.: The color scanning digitizing processing system of precipitation autographic record paper, J. Appl. Meteor. Sci., 15, 737-744, 2004.

Wang, W. Z.: Index of ranfall erosivity $(r)$ in loess area. Soil Water Conserv, China, 12, 34-40, 1987.

Wang, W. Z., Jiao, J. Y., and Hao, X. P.: Distribution of rainfall erosivity R value in China, J. Soil Water Conserv., 9, 5-18, 1995.

Wischmeier, W. H. and Smith, D. D.: Rainfall energy and its relationship to soil loss, T. Am. Geophys. Union, 39, 285-291, 1958.

Wischmeier, W. H. and Smith, D. D.: Predicting rainfall-erosion losses from cropland east of the Rocky Mountains, Agriculture Handbook 282, US Department of Agricultural Research Service, Agricultural Research Service, Washington DC, 1965.

Wischmeier, W. H. and Smith, D. D.: Predicting rainfall erosion losses: A guide to conservation planning, Agriculture Handbook 537, US Department of Agricultural, Agricultural Research Service, Washington DC, 1978.

$\mathrm{Wu}, \mathrm{S}$. Y.: Simplified method on calculation of runoff erosion force in Dabieshan mountainous area and its temporal and spatial distribution, Soil Water Conserv. China, 4, 1-13, 1994.

Xie Y., Zhang, W. B., and Liu, B. Y.: Rainfall erosivity estimation using daily rainfall amount and intensity, Bull. Soil Water Conserv., 6, 53-56, 2001.

Xie Y., Liu B. Y., and Nearing M. A.: Practical thresholds for separating erosive and non-erosive storms, T. ASAE, 45, 1843-1847, 2002.

Xie, Y., Yin, S. Q., Liu, B. Y., Nearing, A. M., and Zhao, Y.: Models for estimating daily rainfall erosivity, J. Hydrol., in review, 2015.

Yin, S. Q., Xie, Y., Nearing, M. A., and Wang, C. G.: Estimation of rainfall erosivity using 5- to 60-minute fixed-interval rainfall data from China, Catena, 70, 306-312, 2007.

Yu, B.: Rainfall erosivity and its estimation for Australia's tropics, Aust. J. Soil Res., 36, 143-165, 1998.

$\mathrm{Yu}, \mathrm{B}$. and Rosewell, C. J.: A robust estimator of the R-factor for the universal soil loss equation, T. ASAE, 39, 559-561, 1996.

Zhang, W. B. and Fu, J. S.: Rainfall erosivity estimation under different rainfall amount, Resour. Sci., 25, 35-41, 2003.

Zhang, W. B., Xie, Y., and Liu, B. Y.: Estimation of rainfall erosivity using rainfall amount and rainfall intensity, Geogr. Res., 21, 384 390, 2002a.

Zhang, W. B., Xie, Y., and Liu, B. Y.: Rainfall erosivity estimation using daily rainfall amounts, Sci. Geogr. Sin., 22, 705-711, 2002b.

Zhou, F. J., Chen, M. H., and Lin, F. X.: The rainfall erosivity index in Fujian province, J. Soil Water Conserv., 9, 13-18, 1995. 